\title{
Integrated model of the production of soluble microbial products (SMP) and extracellular polymeric substances (EPS) in anaerobic chemostats during transient conditions
}

\author{
Sérgio F. Aquino ${ }^{\mathrm{a}, *}$, David C. Stuckey ${ }^{\mathrm{b}}$ \\ ${ }^{\text {a }}$ Chemistry Department, Ouro Preto Federal University (UFOP), Campus Morro do Cruzeiro, Ouro Preto, MG 35.400.000, Brazil \\ ${ }^{\mathrm{b}}$ Department of Chemical Engineering and Chemical Technology, Imperial College London, Prince Consort Road, London SW7 2BY, UK
}

Received 26 June 2006; received in revised form 10 April 2007; accepted 22 June 2007

\begin{abstract}
A model to predict the accumulation of soluble microbial products (SMP) in anaerobic chemostats during steady-state and transient conditions is presented in this paper. The model incorporates the concept of production and degradation of extracellular polymeric substances (EPS or ECP) as part of SMP, and was used to predict SMP production during hydraulic and organic shock load experiments in anaerobic continuously stirred tank reactors (CSTRs). For most variables the model predicted reasonably well the shock loads, and the best-fit values of the main parameters provided valuable information on the types of SMP that predominate under particular culture conditions. According to the model, during steadystate conditions $\sim 58 \%$ of the SMP are utilization-associated products (UAP) whilst $\sim 42 \%$ are biomass-associated products (BAP) of which $\sim 7 \%$ are soluble EPS (sEPS). During the hydraulic and organic shock loads the importance of BAP and sEPS decreases and the UAP accounts for up to $95 \%$ of the SMP.
\end{abstract}

(C) 2007 Elsevier B.V. All rights reserved.

Keywords: Anaerobic digestion; Modelling; Shock loads; Soluble microbial products; Extracellular polymeric substances; Extracellular polymers

\section{Introduction}

It is well known that anaerobic reactors run under stressed (sub-optimal) conditions accumulate volatile fatty acids (VFA), and that VFAs mostly contribute to the residual soluble COD in the effluent under such conditions. On the other hand, under non-stressed conditions, there is no VFA accumulation and the effluent COD may be comprised of non-degraded feed material and soluble microbial products (SMP). Many researchers have shown that for anaerobic reactors fed on simple biodegradable feed like acetate or glucose, the SMP predominate in the effluent and dictate the soluble effluent COD. As a result, models that aim to predict the effluent COD in anaerobic and aerobic systems need to take into account the formation and degradation of SMP.

Rittmann et al. [1] proposed a model to describe the impact of sludge retention time (SRT) and organic loading on effluent SMP. The model assumed that the kinetics of degradation of

\footnotetext{
* Corresponding author. Tel.: +55 313559 1837; fax: +55 3135591636 .

E-mail addresses: sergio@iceb.ufop.br (S.F. Aquino), d.stuckey@imperial.ac.uk (D.C. Stuckey).
}

SMP originating from substrate utilization (UAP) and biomass decay (BAP) were the same, and Kuo et al. [2] used that model to predict the accumulation of SMP in anaerobic chemostats. Noguera et al. [3] used radiolabelled glucose and acetate to follow the production of UAP and BAP in anaerobic chemostats, and by fitting their proposed mathematical model to experimental data they showed the importance of SMP formation and degradation in anaerobic systems. This model showed that most of the SMP accumulation corresponded to BAP, which is related to endogenous decay and has slower degradation rates compared to UAP, and suggested that the decrease in acidogenic biomass was due to SMP formation rather than oxidation to carbon dioxide.

Barker and Stuckey [4] further developed the model of Noguera et al. [3] to account for the production of UAP and BAP from methanogenic microorganisms, as well as for the degradation of UAP and BAP by acidogenic microorganisms. Barker and Stuckey [4] followed the degradation of different radiolabelled substrates in different reactors, and through the fitting of a mathematical model to radiolabelled data they obtained the bestfit for the parameters that represented the production $\left(k_{1}\right.$ and $\left.k_{2}\right)$ and degradation ( $k_{\mathrm{uap}}$ and $k_{\mathrm{bap}}$ ) of UAP and BAP, respectively. 
From the experiments with different feed strengths, the bestfit suggested that the concentration of UAP increased with an increase in $S_{0}$, whilst for BAP the opposite was observed. It was also found that the first-order constant for BAP degradation was lower than that for UAP, indicating that BAPs are more difficult to degrade and that at steady-state they should form the bulk of the SMP. These authors also carried out experiments with different feed compositions in different systems (fill-and-draw reactor and CSTR), and showed that the production of SMP is a complex phenomenon, and that the type of SMP that dominates in any particular system depends not only on the strength of the feed, but also on the composition of the feed and the type of reactor.

In 2004 Laspidou and Rittmann [5,6] published a paper in which they propose a unified theory coupling the production and degradation of SMP with the formation of extracellular polymeric substances (EPS or ECP) for aerobic systems. Amongst the many assumptions the authors had to make, the unified theory proposes that: (i) SMP and soluble EPS are identical in systems in which hydrolysis is not important; (ii) bound EPS are hydrolyzed to form BAP, and the authors consider this the only significant source of BAP; (iii) the formation of bound EPS is growth-associated, and is produced in direct proportion to substrate utilization.

One weakness of the unified theory is that it assumes that all soluble EPS is both UAP and BAP, in other words, soluble EPS and SMP are the same. Ramesh et al. [7] put the unified theory to test and compared the physicochemical characteristics of the SMP and soluble EPS harvested from different sludges, and concluded that the results obtained could not support the hypothesis that SMP is identical to the soluble EPS. Besides EPS and its hydrolysis products, other soluble intracellular components may end up in the bulk solution due to renewal and turnover of internal structures, cell lysis, or as a result of survival strategies adopted by microorganisms [8]. For instance, there is evidence in the literature that some SMP may be deliberately excreted to play a role in quorum sensing (cell-to-cell communication), to pump unwanted metals out of the cell and ensure homeostasis through efflux systems, and to scavenge scarce metal nutrients, as demonstrated in aerobic bacteria which excrete siderophores during an 'iron crisis' [9-13].

The few available data on EPS modeling shows that different strategies have been adopted to model its accumulation and this is mainly due to a lack of data regarding the kinetics of EPS production and degradation. Kreft and Wimpenny [14] developed a model of biofilm growth and considered that EPS production was described by a growth rate dependent and an independent term, whose rates and yields were given by Robinson et al. [15]. Horn et al. [16] modeling aerobic biofilms considered that the production of EPS was coupled to the growth of microorganisms. The authors adopted values of $1.4 \mathrm{gEPS} / \mathrm{g} X$ for $Y_{\text {EPS }}$ and $0.34 \mathrm{~d}^{-1}$ for $K_{\text {D_EPS }}$, which are the yield coefficient for EPS production and the rate of EPS degradation, respectively. In the model used by Kommedal et al. [17] to simulate EPS production in a chemostat, the authors did not consider the degradation of EPS, and growth and non-growth related specific formation rates of $0.18 \mathrm{~g} C_{\text {EPS }} / \mathrm{g} C_{\text {cell }} \mathrm{h}\left(\sim 4.3 \mathrm{~d}^{-1}\right)$ and
$0.03 \mathrm{~h}^{-1}\left(\sim 0.7 \mathrm{~d}^{-1}\right)$ were estimated, respectively. In addition, the authors found that the exogenous (production from glucose) and endogenous EPS yields were $0.77 \mathrm{~g} C_{\mathrm{EPS}} / \mathrm{g} C_{\mathrm{glu}}$ and $0.79 \mathrm{~g} C_{\text {EPS }} / \mathrm{g} C_{\text {cell }}$, respectively. Laspidou and Rittmann [18] also developed a model of biofilm density for aerobic systems, building on their unified theory [5,6], and considered that EPS production was proportional to the substrate utilization rate $\left(K=0.18 \mathrm{mgCOD} \mathrm{EPS}_{\mathrm{mgCOD}} / \mathrm{mubstrate}\right)$, and that EPS degradation followed a first order decay $\left(k_{\text {hyd }}=0.17 \mathrm{~d}^{-1}\right)$.

As SMP and EPS are microbially produced, and are not active cells, they represent a diversion of electrons and carbon that could otherwise be invested in cell yield and growth rate $[5,6]$, hence ignoring SMP and EPS formation could lead to a general overestimation of true cellular growth rates. In addition, both SMP and the soluble component of EPS contribute to the residual soluble COD, and do, in many cases, set the lower limit for the effluent quality.

Therefore, the objective of this paper was to further develop the model proposed by Barker and Stuckey [4] by incorporating the concept of formation and degradation of EPS as suggested by Laspidou and Rittmann [5,6] in their unified theory. In this study the parameters obtained by Barker and Stuckey [4] for steadystate anaerobic chemostats fed on glucose $(10 \mathrm{~g} / \mathrm{L})$ were used to predict both steady-state and the transient conditions under organic and hydraulic shock loads. The model output was then compared with experimental data to verify whether the model could satisfactorily predict the accumulation of SMP observed during both steady-state and shock loads.

\subsection{Model development}

The mathematical model proposed here differs from that presented by Barker and Stuckey [4] in many ways. The proposed model incorporates the concept of formation and degradation of EPS, and allows for the quantification of the relationships between solid species (bacteria and bound EPS) and soluble components (UAP, BAP, soluble EPS, original substrate and intermediate products) during non-steady state conditions. In addition, it is assumed here that all electron donor utilization rates, i.e., the rate of utilization of glucose, acetate, UAP and BAP ( $r_{\text {utsub }}, r_{\text {utac }}, r_{\text {utuap }}$ and $r_{\text {utbap }}$ ) are based on Monod kinetics. The model is for a single completely mixed reactor in which concentrations of all species are uniform; hence mass transfer resistances are not included. The model concept and framework are presented in Figs. 1 and 2.

Fig. 1 shows that the substrate entering the acidogenic/acetogenic biomass $\left(X_{\mathrm{a}}\right)$ can take different paths. The substrate is used for synthesis of biomass (path 1) which generates VFAs (path 8) and UAP (path 2). The biomass in turn produces bound EPS (path 3), undergoes endogenous decay (path 10), and releases cell lysis products (path 4). Bound EPS may be stripped off the cell or hydrolysed contributing to BAP formation (path 5), and it is considered here that both soluble EPS and cell lysis products are the sources of BAP. This is the main conceptual difference between this model and the unified theory proposed by Laspidou and Rittmann [5,6] for aerobic systems. As discussed before in the unified 




1 - biomass synthesis

2 - UAP formation

3 - formation of bound EPS (EPS $\mathrm{X}_{\mathrm{a}}$ and $\mathrm{EPS}_{\mathrm{X}_{\mathrm{m}}}$ )

4 - formation of BAP through cell lysis

5 - formation of soluble EPS (part of BAP) via hydrolysis/shear of bound EPS

6 - degradation of UAP by acidogenic/acetogenic bacteria

7 - degradation of BAP by acidogenic/acetogenic bacteria

8 - formation of intermediate products (acetate as the main intermediate)

9 - formation of methanogenic end products

10 - biomass endogenous decay (maintainance, autooxidation)

Fig. 1. Schematic of electron flow from original substrate.

theory, hydrolysis of EPS is considered the only source of BAP.

As far as methanogenesis is concerned, acetate is considered the main intermediate formed and used by methanogenic biomass $\left(X_{\mathrm{m}}\right)$, which also produces UAP, bound EPS, cell lysis products and the end products methane and carbon dioxide. Similarly to the models proposed by Laspidou and Rittmann $[5,6]$,

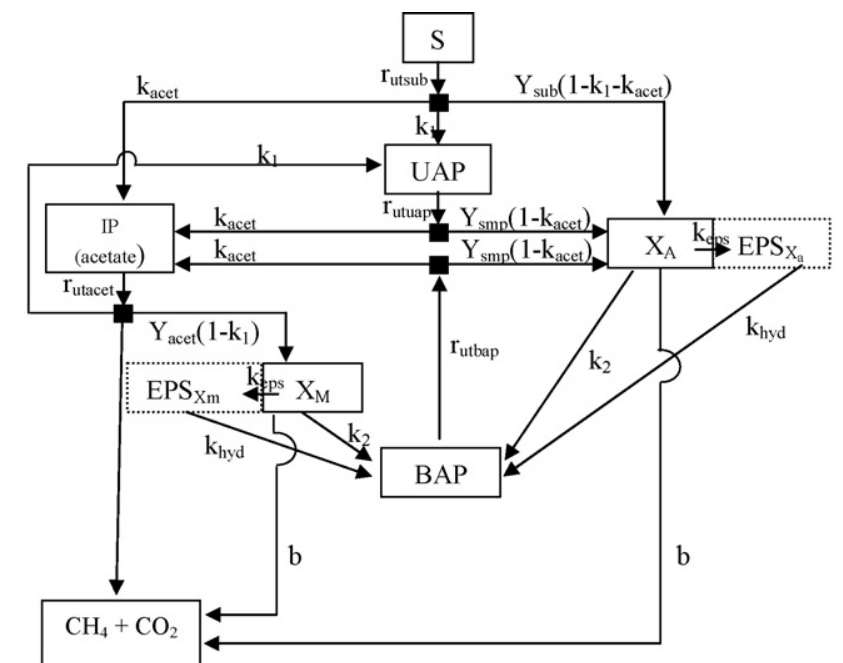

$\mathrm{b}$ - Biomass decay coefficient $\left(\mathrm{d}^{-1}\right)$

$\mathrm{k}_{1}$ - UAP formation constant $\left(\mathrm{mgCOD}_{\text {smp }} / \mathrm{mgCOD}_{\text {substrate }}\right)$

$\mathrm{k}_{2}$ - BAP formation constant $\left(\mathrm{d}^{-1}\right)$

$\mathrm{k}_{\text {acet }}$ - Acetate formation constant $\left(\mathrm{mgCOD}_{\text {acetate }} / \mathrm{mgCOD}_{\text {substrate }}\right)$

$\mathrm{k}_{\text {eps }}-$ EPS formation constant $\left(\mathrm{mgCOD}_{\mathrm{eps}} / \mathrm{mgCOD}_{\text {cell }}-\mathrm{d}\right)$

$\mathrm{k}_{\text {hyd }}-$ Constant for hydrolysis/shear of bound EPS $\left(\mathrm{d}^{-1}\right)$

$\mathrm{r}_{\text {utsub }}$ - rate of substrate utilization $\left(\mathrm{mgCOD}_{\text {substrate }} / \mathrm{mgCOD}_{\text {cell }}-\mathrm{d}\right)$

$\mathrm{r}_{\text {utacet }}$ - rate of acetate utilization $\left(\mathrm{mgCOD}_{\text {acetate }} / \mathrm{mgCOD}_{\text {cell }}-\mathrm{d}\right)$

$\mathrm{r}_{\text {utuap }}$ - rate of UAP utilization $\left(\mathrm{mgCOD}_{\text {uap }} / \mathrm{mgCOD}_{\text {cell }}-\mathrm{d}\right)$

$r_{\text {utbap }}$ - rate of BAP utilization $\left(\mathrm{mgCOD}_{\text {bap }} / \mathrm{mgCOD}_{\text {cell }}-\mathrm{d}\right)$

$\mathrm{Y}_{\mathrm{smp}}$ - yield of $\mathrm{X}_{\mathrm{a}}$ biomass from SMP utilization $\left(\mathrm{mgCOD}_{\mathrm{cell}} / \mathrm{mgCOD}_{\mathrm{smp}}\right)$

$\mathrm{Y}_{\mathrm{sub}}$ - yield of $\mathrm{X}_{\mathrm{a}}$ biomass from substrate utilization $\left(\mathrm{mgCOD}_{\text {cell }} / \mathrm{mgCOD}_{\text {substos }}\right)$

$\mathrm{Y}_{\text {acet }}$ - yield of $\mathrm{X}_{\mathrm{m}}$ biomass from acetate utilization $\left(\mathrm{mgCOD}_{\text {cell }} / \mathrm{mgCOD}_{\text {acetatc }}\right)$

Fig. 2. Structure of the model proposed in this study. and by Barker and Stuckey [4], this model includes the recycling of UAP and BAP (path 6 and 7) through their utilization by acidogenic biomass. It has also been assumed that the degradation of UAP and BAP by $X_{\mathrm{a}}$ produces new $X_{\mathrm{a}}$ and intermediate products (IP), but does not lead to the production of new UAP or BAP, and this assumption was also employed by different research groups [4-6,19,20].

Fig. 2 shows the structure of the model in terms of flow of electrons from the donor substrate (S). This structure is similar to that proposed by Barker and Stuckey [4] but it builds complexity since now the biomass $\left(X_{\mathrm{a}}\right.$ and $\left.X_{\mathrm{m}}\right)$ uses part of the energy and carbon source to produce bound EPS which can be detached from the cell resulting in biomass loss and BAP formation. The model proposed is described by the following mass balance equations:

$$
\begin{aligned}
& \frac{\mathrm{d} S}{\mathrm{~d} t}=\frac{S_{0}-S}{\theta}-r_{\mathrm{utsub}} X_{\mathrm{a}} \\
& \frac{\mathrm{dIP}}{\mathrm{d} t}=\left[k_{\text {acet }}\left(r_{\mathrm{utsub}}+r_{\text {utuap }}+r_{\text {utbap }}\right)\right] X_{\mathrm{a}}-r_{\text {utacet }} X_{\mathrm{m}}-\frac{\mathrm{IP}}{\theta}
\end{aligned}
$$

$$
\begin{aligned}
\frac{\mathrm{d} X_{\mathrm{a}}}{\mathrm{d} t}= & {\left[r_{\mathrm{utsub}} Y_{\text {sub }}\left(1-k_{1}-k_{\mathrm{acet}}\right)+r_{\text {utuap }} Y_{\text {smp }}\left(1-k_{\text {acet }}\right)\right.} \\
& \left.+r_{\text {utbap }} Y_{\text {smp }}\left(1-k_{\text {acet }}\right)\right] X_{\mathrm{a}}-\frac{X_{\mathrm{a}}}{\theta}-b X_{\mathrm{a}}-k_{2} X_{\mathrm{a}} \\
& -k_{\text {hyd }} \mathrm{EPS}_{X_{\mathrm{a}}}
\end{aligned}
$$

$$
\frac{\mathrm{d} X_{\mathrm{m}}}{\mathrm{d} t}=r_{\mathrm{utac}} Y_{\text {acet }}\left(1-k_{1}\right) X_{\mathrm{m}}-\frac{X_{\mathrm{m}}}{\theta}-b X_{\mathrm{m}}-k_{2} X_{\mathrm{m}}
$$$$
-k_{\text {hyd }} \mathrm{EPS}_{X_{\mathrm{m}}}
$$

$$
\frac{\mathrm{dUAP}}{\mathrm{d} t}=\left(k_{1} r_{\mathrm{utsub}} X_{\mathrm{a}}+k_{1} r_{\mathrm{utacet}} X_{\mathrm{m}}\right)-\frac{\mathrm{UAP}}{\theta}-r_{\mathrm{utuap}} X_{\mathrm{a}}
$$

$$
\begin{aligned}
\frac{\mathrm{dBAP}}{\mathrm{d} t}= & k_{2} X_{\mathrm{a}}+k_{2} X_{\mathrm{m}}+k_{\mathrm{hyd}}\left(\mathrm{EPS}_{X_{\mathrm{a}}}+\mathrm{EPS}_{X_{\mathrm{b}}}\right)-\frac{\mathrm{BAP}}{\theta} \\
& -r_{\text {utbap }} X_{\mathrm{a}}
\end{aligned}
$$

$\frac{\mathrm{dEPS}_{X_{\mathrm{a}}}}{\mathrm{d} t}=k_{\mathrm{ecp}} X_{\mathrm{a}}-\frac{\mathrm{EPS}_{X_{\mathrm{a}}}}{\theta}-k_{\mathrm{hyd}} \mathrm{EPS}_{X_{\mathrm{a}}}$

$\frac{\mathrm{dEPS}_{X_{\mathrm{m}}}}{\mathrm{d} t}=k_{\mathrm{ecp}} X_{\mathrm{m}}-\frac{\text { EPS }_{X_{\mathrm{m}}}}{\theta}-k_{\mathrm{hyd}} \mathrm{EPS}_{X_{\mathrm{m}}}$

$\mathrm{Sol}=S+\mathrm{IP}+\mathrm{UAP}+\mathrm{BAP}$

$X_{\mathrm{T}}=X_{\mathrm{a}}+X_{\mathrm{m}}$

solEPS $=k_{\text {hyd }}\left(\operatorname{EPS}_{X_{\mathrm{a}}}+\operatorname{EPS}_{X_{\mathrm{m}}}\right)$

All rate utilization equations were formulated as a Monod type as shown by Eqs. (12)-(15).

$r_{\mathrm{utsub}}=\frac{q_{\mathrm{s}} S}{K_{\mathrm{s}}+S}$

$r_{\text {utacet }}=\frac{q_{\mathrm{IP}} \mathrm{IP}}{K_{\mathrm{IP}}+\mathrm{IP}}$ 
$r_{\text {utuap }}=\frac{q_{\text {uap }} \mathrm{UAP}}{K_{\text {uap }}+\mathrm{UAP}}$

$r_{\text {utbap }}=\frac{q_{\text {bap }} \text { BAP }}{K_{\text {bap }}+\text { BAP }}$

It can be seen in Eqs. (3) and (4) that the yield ( $\left.Y_{\text {sub }}\right)$ of acidogenic/acetogenic biomass is decreased by a factor $\left(1-k_{1}-k_{\text {acet }}\right)$ since part of the substrate electrons are diverted to the production of UAP $\left(k_{1}\right)$ and intermediate products ( $\left.k_{\text {acet }}\right)$. Similarly, the yield $\left(Y_{\text {acet }}\right)$ of methanogenic biomass is decreased by a factor $\left(1-k_{1}\right)$ since part of substrate electrons are diverted to UAP formation. For aerobic systems, Laspidou and Rittmann $[5,6]$ discounted the biomass yield by a factor $\left(1-k_{1}-k_{\mathrm{EPS}}\right)$ because they considered EPS not to be a part of the 'active biomass', where $k_{\mathrm{EPS}}\left(M_{\mathrm{EPS}} / M_{x}\right)$ represents electron diversion towards EPS production. In the model proposed here EPS is part of the biomass, and biomass loss occurs only when the EPS is sloughed off the cell, or hydrolysed to become soluble, and this factor is accounted for by adding the terms $-k_{\mathrm{EPS}} \mathrm{EPS}_{X_{\mathrm{a}}}$ and $-k_{\mathrm{EPS}} \mathrm{EPS}_{x_{\mathrm{m}}}$ to Eqs. (3) and (4), respectively. Eqs. (7) and (8) show that the formation of EPS was not considered to be proportional to the substrate utilization rate as proposed by the unified theory of Laspidou and Rittmann [5,6], instead EPS was considered to be a non-growth-associated product. If EPS production was proportional to the rate of substrate utilization, EPS concentration would be unrealistically high during the transient conditions of organic shock loads, and experimental data obtained in our laboratory shows that this was not the case [21]. Since the kinetics of EPS hydrolysis are poorly characterized, a simple but reasonably reliable approach which employs a first-order relationship with respect to EPS, where the first-order hydrolysis rate coefficient is $k_{\text {hyd }}\left(T^{-1}\right)$, was used according to the unified theory.

It was assumed here that the rate of intermediate products formation $\left(k_{\text {acet }}\right)$ from the degradation of UAP and BAP was the same as that from the degradation of the original substrate (Eq. (2)). In addition, it was assumed that the yield of acidogenic biomass $\left(Y_{\mathrm{smp}}\right)$ from the utilization of UAP was the same as BAP, and that $Y_{\text {smp }}$ was different from the biomass yield resulting from the utilization of the original substrate $\left(Y_{\text {sub }}\right)$. This assumption was not employed by Barker and Stuckey [4] who considered the same acidogenic biomass yield for utilization of glucose, UAP and BAP, but was used by Laspidou and Rittmann $[5,6]$.

To solve the model Eqs. (1)-(8) were discretized, and the solution marched forward in time with a small time step $\delta t$. The discretization of the equations was accomplished based on the following scheme:

$\frac{\mathrm{d} A}{\mathrm{~d} t}=B$

and then

$A^{t}=A^{t-1}+B^{t-1} \delta t$

where $A$ is a variable, $B$ the time derivative of $A$, and $\delta \mathrm{t}$ is the time step. The superscript $t$ indicates the value of variable $A$ at time $t$, and $t-1$ indicates the value of that variable at the previous time step, i.e., $t-\delta t$.

If the model is run for a long period of time with constant input, all species eventually achieve steady-state conditions (see Fig. 3). For shorter times, or with changing input conditions, the model describes the system's transient response. The discretized model equations were solved using a spreadsheet (Microsoft Excel) with a time step of $0.01 \mathrm{~d}$. For the steady-state simulation the HRT was fixed at $15 \mathrm{~d}$, the initial substrate concentration $\left(S_{0}\right)$ was $10 \mathrm{gCOD} / \mathrm{L}$, and the model was run for $90 \mathrm{~d}$ (6 HRT's). For the organic shock load simulation the concentration of $S_{0}$ was suddenly changed so that an effluent concentration $(S)$ of $4 \mathrm{gCOD} / \mathrm{L}$ was obtained, and during hydraulic shock simulation the HRT was made a variable and changed from $15 \mathrm{~d}$ to $7.5 \mathrm{~d}$ and then to $3 \mathrm{~d}$. These conditions simulate the experiments with organic and hydraulic shock loads presented and discussed in Aquino and Stuckey [21].
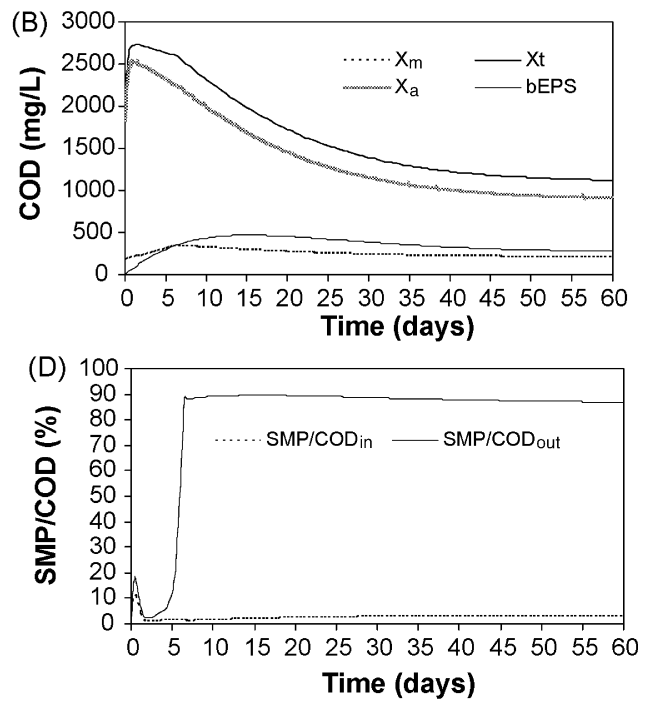

Fig. 3. Model output for steady-state conditions using parameter values presented in Table 1. 
Table 1

Parameter values for the mass-balance equations

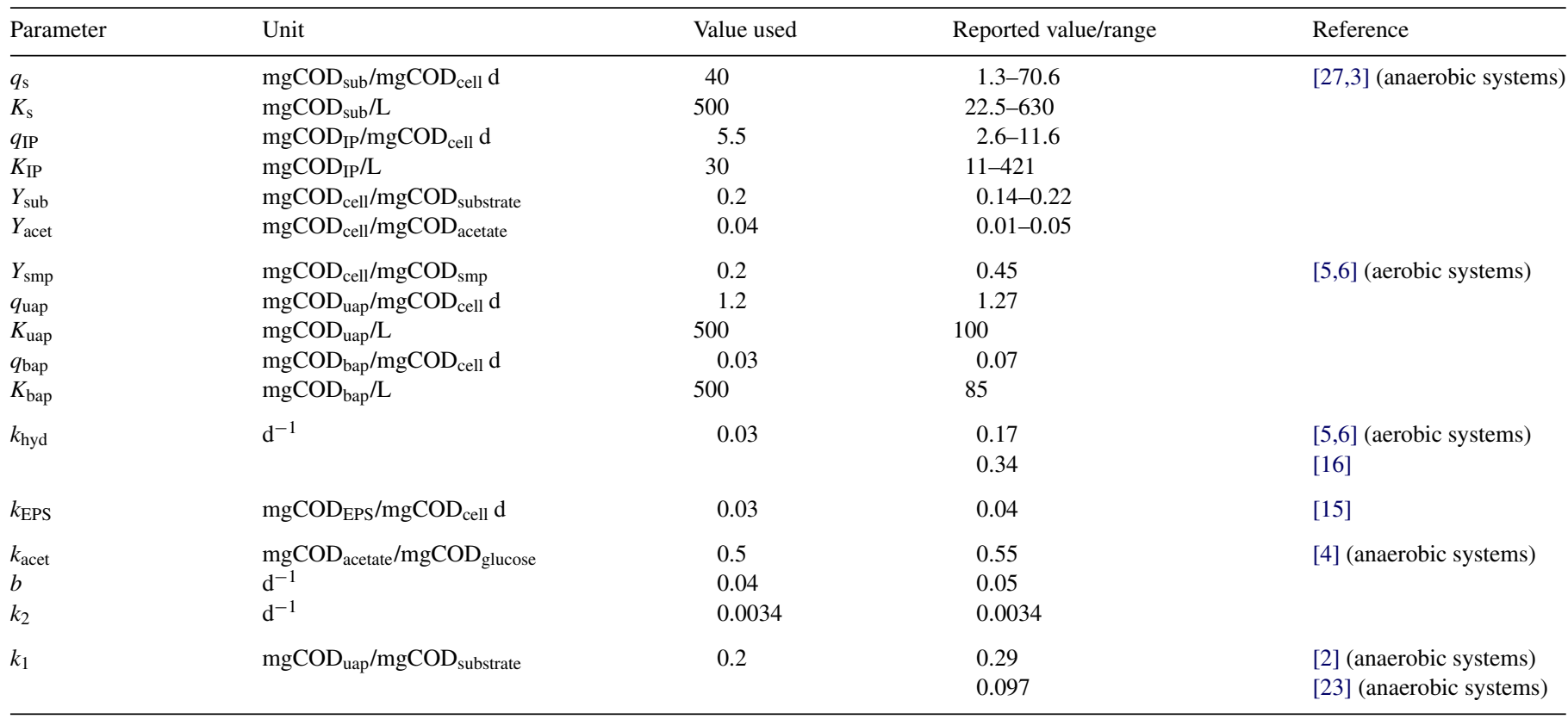

\section{Results and discussion}

\subsection{Steady-state condition}

The model was first run using the parameter values reported in the literature as shown in Table 1 . The parameter values were then adjusted slightly so that the model output during steadystate simulation (Fig. 3) fitted typical experimental data range, as presented in Table 2.

Data on the kinetics of SMP formation and degradation is scarce in the literature, especially for anaerobic systems. As a result, the values of $q_{\text {uap }}, q_{\text {bap }}, K_{\text {uap }}$ and $K_{\text {bap }}$ used here were based on those used by Laspidou and Rittmann [5,6] for aerobic systems. Table 1 shows that the values of $K_{\text {uap }}$ and $K_{\text {bap }}$ used here were higher than those used in the unified theory. However, the values used were the ones which better predicted the SMP concentration, and it is well known that $K_{\mathrm{S}}$ values for anaerobic systems are much higher than for aerobic systems.

Table 2

Average concentration and range of main variables for $S_{0}=10 \mathrm{gCOD} / \mathrm{L}$ in anaerobic chemostats operated at steady-state conditions

\begin{tabular}{lllc}
\hline Variable & $\begin{array}{l}\text { Average value } \\
(\mathrm{mg} / \mathrm{L})\end{array}$ & $\begin{array}{l}\text { Typical range }^{\mathrm{a}} \\
(\mathrm{mg} / \mathrm{L})\end{array}$ & $\begin{array}{l}\text { Estimated average } \\
\text { value }^{\mathrm{b}}(\mathrm{mgCOD} / \mathrm{L})\end{array}$ \\
\hline Residual glucose & N.D. $^{\mathrm{c}}$ & N.D.-20 & 12 \\
SMP & 300 & $200-400$ & 290 \\
VFA & N.D. & N.D.-50 & 30 \\
VSS & 1800 & $1500-2200$ & 1150 \\
Bound EPS & 350 & $225-700$ & 280 \\
bEPS/VSS & 0.3 & $0.2-0.4$ & 0.33
\end{tabular}

\footnotetext{
a From experimental data reported elsewhere [8,21].

b According to simulation presented in Fig. 3.

c N.D.: not detected.
}

The value of $k_{\text {EPS }}$ was adopted so that the model yielded at steady-state a ratio of bound EPS to biomass (bEPS/VSS) close to 0.3 which is the average ratio of protein-like EPS to biomass $\left(\mathrm{bEPS}_{\mathrm{p}} / \mathrm{VSS}\right)$ obtained experimentally [21]. The value of $k_{\text {EPS }}$ that best fitted the experimental data was $0.03 \mathrm{~d}^{-1}$, and as can be seen in Table 1 this value was very close to that determined by Robinson et al. [15]. As far as the hydrolysis of EPS was concerned it was not possible to determine the value of $k_{\text {hyd }}$ experimentally, and the value 0.17 used by Laspidou and Rittmann [5,6] was first tried. This value proved to be too high since it resulted in high $X_{\mathrm{m}}$ loss, and non-realistic IP accumulation. The initial value was then reduced to $0.03 \mathrm{~d}^{-1}$ which yielded better fit for the variables presented in Table 2. The value of $k_{\text {hyd }}$ used suggests that $3 \%$ of the bound EPS (or $1 \%$ of VSS) was daily hydrolysed or shorn off the cell matrix to produced soluble EPS, and this is consistent with the findings of Sheng et al. [22] who found that $1.38 \%$ of the VSS was released as soluble EPS after $180 \mathrm{~min}$ shear at $G=800 \mathrm{~s}^{-1}$.

Fig. 3 shows the model predictions for steady-state; for most of the variables the prediction is in relatively good agreement with typical experimental values presented in previous chapters, and summarized in Table 2. According to the model the predicted steady-state concentrations of SMP, VFA and residual substrate are $290 \mathrm{mgCOD} / \mathrm{L}, 30 \mathrm{mgCOD} / \mathrm{L}$ and $12 \mathrm{mg} / \mathrm{L}$. In this scenario SMP would constitute $87 \%$ of the residual COD, whilst non-degraded substrate and VFAs would make up $9 \%$ and $4 \%$ of the residual COD, respectively, and this agrees well with experimental data [21]. In fact for most of the systems studied, VFAs and original substrate were not detected at steady-state; hence the model parameters could still be slightly modified by increasing the rate of substrate and VFA degradation. 

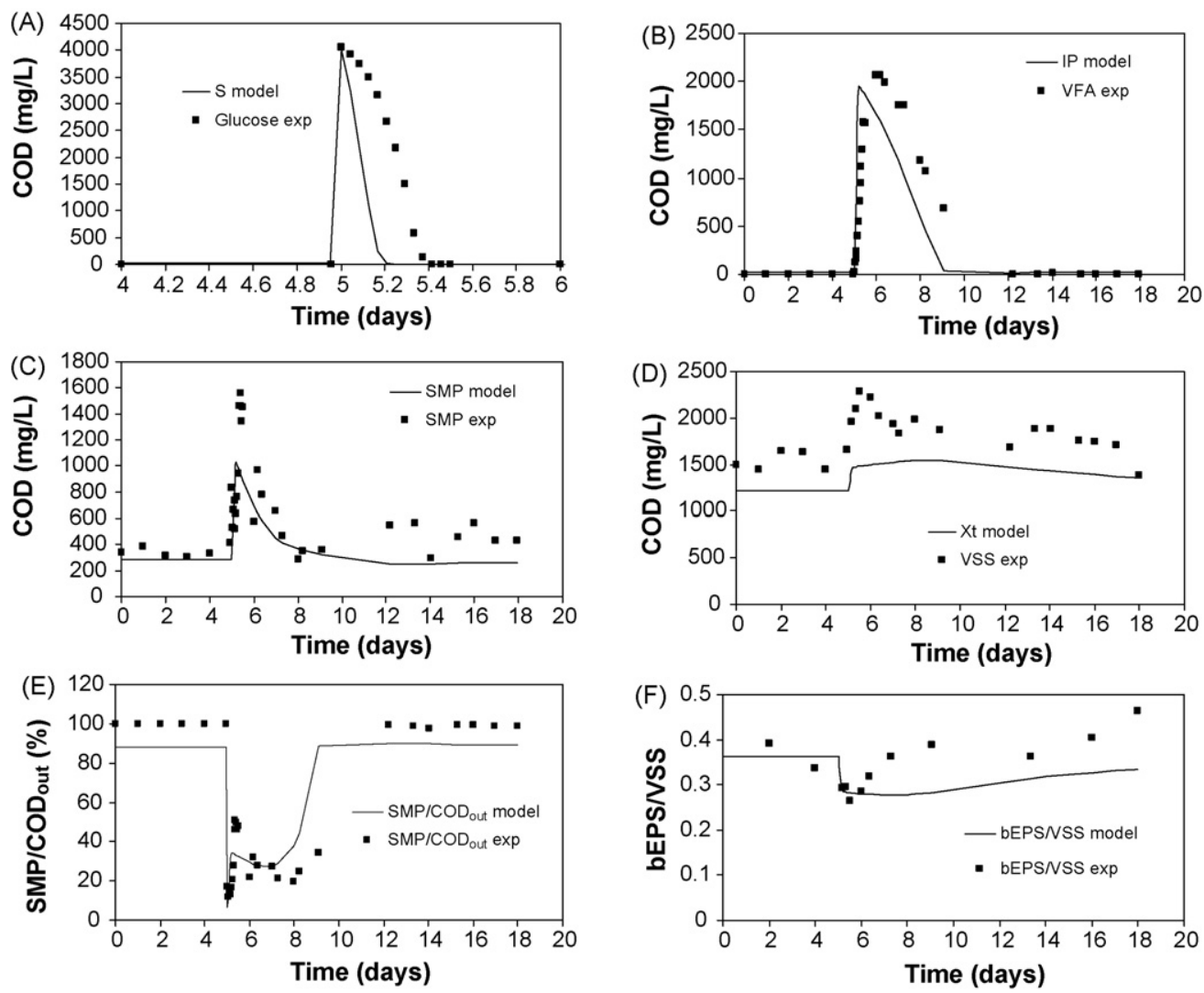

Fig. 4. Simulation of organic shock load by a sudden glucose spike on day 5 (continuous line) and experimental data (square dots).

According to the model, at steady steate, $58 \%$ of the SMP should be due to UAP and $42 \%$ to BAP, and this is also in agreement with other researchers $[3,4]$. The model suggests that bound EPS would constitute $\sim 25 \%$ of the volatile suspended solids (VSS), and that $\sim 3 \%$ of the bound EPS would lead to the formation of soluble EPS, and these are in agreement with experimental data [21]. According to the model, the soluble EPS would constitute $\sim 7 \%$ of the BAP and only $3 \%$ of the SMP since the main source of SMP would be products released into the bulk solution as a result of the metabolism of substrate (e.g. exoenzymes, siderophores, quorum sensing chemical), as well as from the renewal of cellular structures and cell aging (e.g. nucleic acids, structural proteins).

The model prediction for biomass concentration was not as good as for soluble components. Fig. 3 shows that at steadystate total biomass (as COD) should be $\sim 1200 \mathrm{mg} / \mathrm{L}$, whilst Table 2 shows that the typical VSS concentration (as COD) is $\sim 25 \%$ higher. It should be emphasized that the model considers $X_{\mathrm{t}}$ as the total amount of active biomass, and that the parameter VSS 'catches' everything that is suspended and volatile, i.e., active and inactive biomass as well as particulate matter (e.g. cell debris). Therefore, it is not surprising that the VSS concentration is actually higher than the concentration of $X_{\mathrm{t}}$ predicted by the model. In addition, the model predicts a lower concentration of biomass at steady-state because the yield values ( $Y_{\text {sub }}, Y_{\text {smp }}$ and $Y_{\text {acet }}$ ) were decreased to account for the diversion of electrons for the formation of UAP and intermediate products.

\subsection{Organic shock load}

The organic shock load simulation was accomplished by suddenly increasing the initial concentration of substrate $\left(S_{0}\right)$ so that an effluent substrate concentration $(S)$ of $\sim 4000 \mathrm{mg} / \mathrm{L}$ was obtained, hence reproducing the experimental conditions presented in Aquino and Stuckey [21]. Fig. 4 shows the model output and the experimental data presented in Aquino and Stuckey [21], for a glucose spike on day 5, and it can be seen that for most parameters the fitting was reasonably good. According to the model the concentration of glucose $(S)$ should decrease rapidly and reach $\sim 8 \mathrm{mg} / \mathrm{L}$ just $5 \mathrm{~h}$ after the spike was made, and the experimental data shows that substrate degradation occurred at a slight slower rate (Fig. 4A). The concentration of acetate should increase to a maximum of $\sim 1900 \mathrm{mgCOD} / \mathrm{L}$ by $8 \mathrm{~h}$ after the spike, and then steadily decrease to $\sim 9 \mathrm{mg} / \mathrm{L}$ after $\sim 4 \mathrm{~d}$, whilst the experimental data shows that the VFAs reached its maximum ( $2000 \mathrm{mgCOD} / \mathrm{L})$ $1 \mathrm{~d}$ after the spike, and took $\sim 7 \mathrm{~d}$ to return to steady-state levels.

One weakness of the model proposed here is that it considers that acetate is the main intermediate of the anaerobic process, and whilst this is true for steady-state conditions, under shock loads other intermediate compounds may be as important as, or even more important, than acetate. It can be seen in the data presented in Aquino and Stuckey [21] that the spike of glucose caused the accumulation of not only acetate, but also propionate and butyrate. 
As far as SMP acumulation is concerned, the results presented in Fig. 4C show that a very good fit was obtained for the model output and the experimental data, indicating that the adopted values for the parameters $k_{1}, k_{2}, q_{\text {uap }}$ and $q_{\text {bap }}$, which are very sensitive, are in the right range. In a first simulation, the value of $k_{1}\left(0.097 \mathrm{mgCOD}\right.$ smp $\left./ \mathrm{mgCOD}_{\text {substrate }}\right)$ determined by Barker [23] was used, however, this value underestimated the concentration of SMP during the shock loads, and the value that best fitted the model output to the experimental data was $0.20 \mathrm{mgCOD}$ smp $/ \mathrm{mgCOD}_{\text {substrate }}$. This value is the same value adopted by de Silva and Rittmann [19,20], Urbain et al. [24], Noguera et al. [3], Furumai and Rittmann [25], and Namkung and Rittmann [26] for aerobic systems, and is close to the value of $0.29 \mathrm{mgCOD} \mathrm{smp}_{\mathrm{smgCOD}} / \mathrm{mgbstrate}$ adopted by Kuo et al. [2] when modelling SMP formation in anaerobic systems.

Nevertheless, by adopting either $k_{1}$ values, the increase in SMP over the glucose spike would be mainly due to the formation of UAP, since its formation was proportional to the rate of substrate utilization. This seems to agree with the experimental results presented in Aquino and Stuckey [21] which showed that the concentration of DNA was constant throughout the experiment, indicating that cell lysis was not enhanced during the organic shock load.

Since, in this model, the rate of EPS formation is more related to the biomass concentration than to substrate degradation, the amount of bound EPS did not increase significantly over the glucose spike. One simulation was made by assuming that EPS is a growth-associated product, hence considering the formation of EPS to be proportional to the rate of substrate utilization.
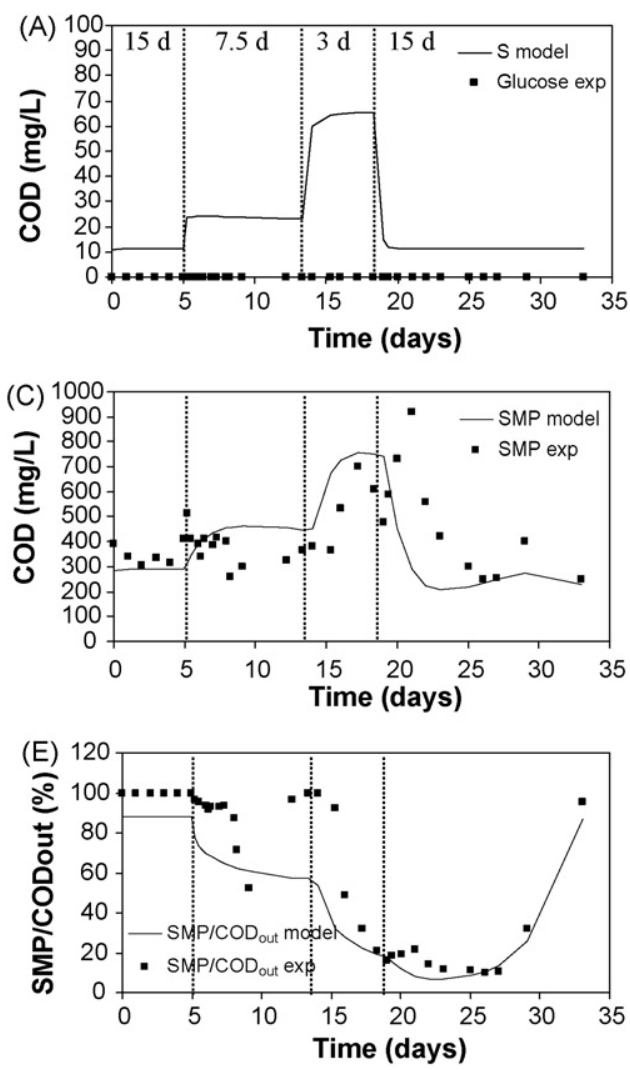

In such a scenario the concentration of bound EPS reached the staggering figure of $6200 \mathrm{mgEPS} \mathrm{COD}_{\mathrm{CO}} / \mathrm{L}$ in the first $3 \mathrm{~h}$ after the glucose spike was made, and then decreased to normal levels after another $3 \mathrm{~h}$. If bound EPS is modelled with a biomassassociated term, like in the model proposed here, EPS formation is equivalent to a 'decay' mechanism, which means that a very high rate of EPS formation would require a high concentration of biomass.

Laspidou and Rittmann [5,6] opted for modelling EPS as a growth-associated product because there was experimental evidence in the literature suggesting that a large accumulation of EPS was possible even when the biomass accumulation was low. However, this is a controversial issue since there are other researchers, also quoted by Laspidou and Rittmann $[5,6]$, who showed that EPS did not increase in periods of higher substrate utilization.

The results presented in Aquino and Stuckey [21] and reproduced in Fig. 4 show that EPS production before and after the glucose spike was not statistically different. Although we did not measure EPS production in the first $6 \mathrm{~h}$ after the glucose spike, the concentration of $6200 \mathrm{mgEPS} \mathrm{COD}_{\mathrm{C}} / \mathrm{L}$ seems to be unrealistically high since it is three times the amount of biomass present in the system just before the spike was made.

\subsection{Hydraulic shock load}

The hydraulic shock load was simulated by changing the hydraulic retention time (HRT) from $15 \mathrm{~d}$ to $7.5 \mathrm{~d}$ on day 5 , and then to $3 \mathrm{~d}$ on day 14 . An HRT of $3 \mathrm{~d}$ was held from day
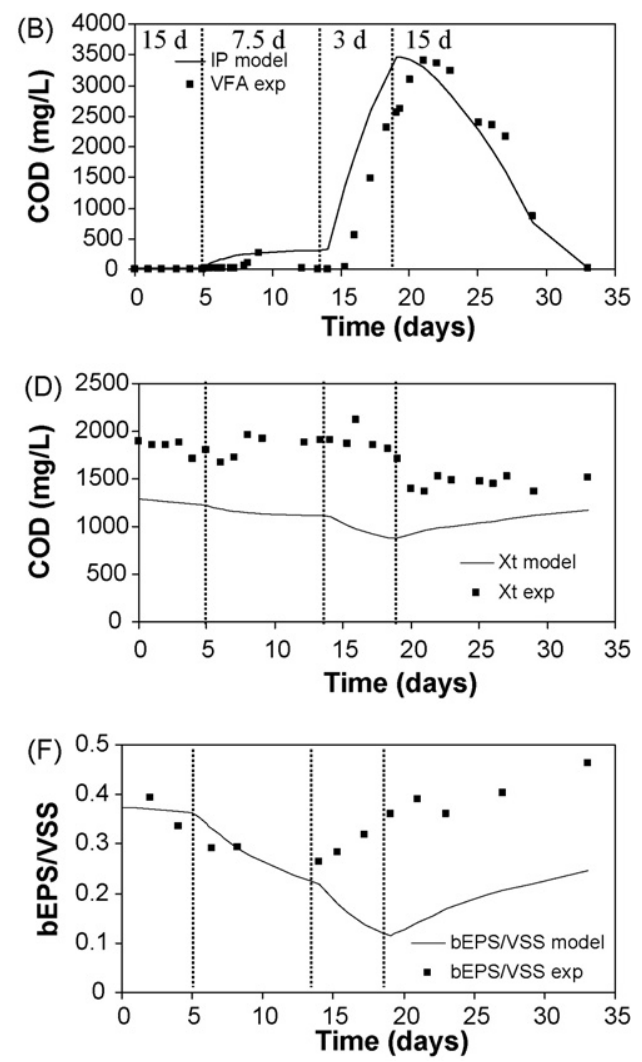

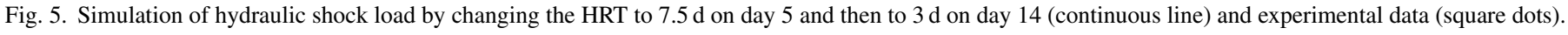



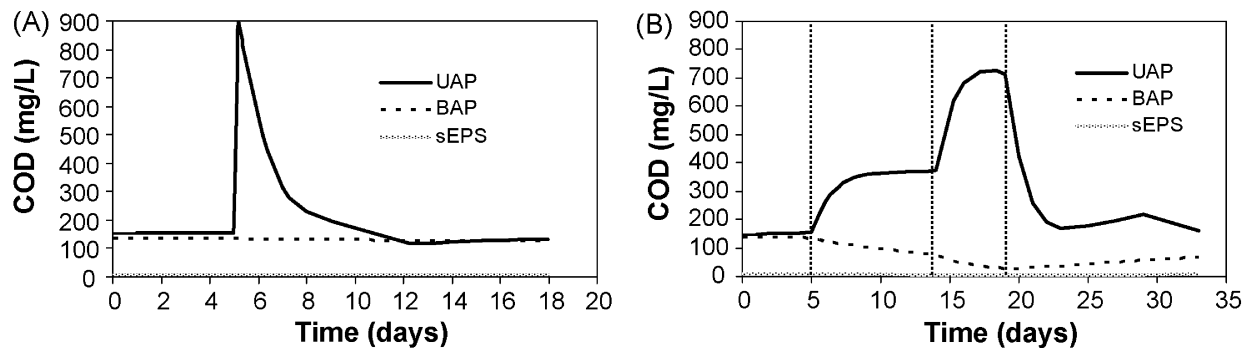

Fig. 6. Model output of the composition of SMP during the organic (A) and hydraulic (B) shock loads.

14 to day 20 and then set back to the original value, reproducing the experimental conditions presented in Aquino and Stuckey [21]. According to the model the reduction of HRT resulted in an increase in the concentration of original substrate (Fig. 5A), however, the experimental data shows that no glucose was detected in the effluent throughout the experiment. Although the model overestimated the glucose degradation during the glucose spike, the contrary was observed when the HRT was reduced. As discussed before, the model parameters were set so that the output could represent steady-state data, mainly for SMP accumulation. The discrepancies observed during the transient conditions may indicate metabolism shift or some kind of biomass limitation during the stressful conditions caused by the shock loads.

Fig. 5B shows that a relatively good fit was obtained for VFA accumulation. As discussed before, the model seemed to overestimate the degradation of VFA after the glucose spike, however, during the hydraulic shock load simulation the predicted VFA concentration was actually higher than measured data, especially during the period the HRT was $3 \mathrm{~h}$. As discussed in Aquino and Stuckey [21], during shock loads there is a shift in glucose metabolism leading to a significant accumulation of propionate and butyrate, and this is not accounted for in the model proposed here. More advanced models, that incorporate the concept of population dynamics and microbial diversity, need to be develop, and molecular biology techniques are, for sure, valuable tools that could be used regarding this issue.

According to the model the SMP concentration should increase from $\sim 290 \mathrm{mg} / \mathrm{L}$ to $470 \mathrm{mg} / \mathrm{L}$ after the HRT was changed from $15 \mathrm{~d}$ to $7.5 \mathrm{~d}$, and such an increase would be mainly due to UAP formation because of the higher substrate utilization rates resulting from the increase in the feed flow. As discussed in Aquino and Stuckey [21], there was no statistically significant difference between the production of SMP at $15 \mathrm{~d}$ and $7.5 \mathrm{~d}$ HRT, but Fig. 5C shows that a further decrease in the HRT to $3 \mathrm{~d}$ resulted in a significant increase in SMP production, and this correlated well with the experimental data. According to the model such an increase would be mainly due to the formation of UAP, since the concentration of BAP would actually decrease because of biomass washout.

As discussed in Aquino and Stuckey [21], the profile of total DNA in the bulk solution intriguingly suggested an increase in cell lysis during the period when the HRT was $3 \mathrm{~d}$. If cell lysis did occur, then the accumulation of BAP might have been more important than the model suggests. It is important to point out that the model proposed here is similar to that proposed by Laspidou and Rittmann [5,6] and by Barker and Stuckey [4] in the sense that it does not account for the enhanced accumulation of SMP observed during stressful conditions. The model proposed here assumes that the biomass has ideal conditions in terms of nutrients, $\mathrm{pH}$ and other growth conditions to metabolise the substrate, so that any SMP production resulting from stressful conditions (low pHs, nutrient deficiency or the presence of toxic compounds), would not be accounted for. It is not straightforward to correlate an eventual induced production of SMP or EPS with non-ideal environmental conditions, or with the concentration of stressing agents, and new models that address these issues need to be developed and tested accordingly.

As far as the biomass and bound EPS concentration are concerned, the model output was not well correlated with experimental data. According to the model the reduction of the HRT from $15 \mathrm{~d}$ to $3 \mathrm{~d}$ should lead to a great biomass loss due to washout, and this would obviously cause a steady decrease in bound EPS. Fig. 5 (D and E) shows that biomass loss was actually lower than predicted in this may indicate that biomass yield $(Y)$ is actually higher than the value adopted in this model.

Fig. 6 summarizes what was discussed in the previous sections and shows the distribution of SMP during the shock loads. It can be seen that during both shock loads, most of SMP should be due to UAP resulting from the increased organic load and substrate metabolism. The amount of BAP should be important only at steady-state conditions, and the soluble EPS should account for no more than 5\% of the SMP during all conditions simulated. In contrast to the unified theory proposed by Laspidou and Rittmann [5,6], the production and hydrolysis of EPS did not dictate SMP accumulation, and this agrees with chromatographic results [7] which showed that EPS hydrolysates do not accumulate in well operated systems. Nevertheless, new experiments need to be devised in order to determine the rate of EPS hydrolysis, and to accurately determine the contribution of soluble EPS to SMP.

\section{Conclusion}

While the model proposed here is a gross simplification of the anaerobic digestion process, it is an improvement on the model proposed by Barker and Stuckey [4], since it takes into account the production of EPS as part of SMP, as well as allowing for the quantification of the soluble and insoluble species during transient conditions. Although some aspects of 
the complex anaerobic sequential process had to be ignored, and assumptions made, the model satisfactorily predicted typical steady-state conditions, and for many variables it described well the transient conditions during organic and hydraulic shock loads.

In general the simulations resulted in a satisfactory representation of the data presented in Aquino and Stuckey [21], and predicted that at steady-state the majority of the residual COD is indeed due to SMP. Under such conditions UAP should comprise $\sim 58 \%$ of the SMP, whilst soluble EPS should represent $\sim 7 \%$ of BAP. Because of their slow degradation rates, BAP should be important only at steady-state, while UAP should determine the SMP production when the rate of substrate degradation is high, as observed during the transient conditions under organic and hydraulic shock loads.

The mathematical model presented here was useful to quantify the relationships between different soluble species, i.e. original substrate, intermediate VFAs, SMP and soluble EPS during steady-state and transient conditions. In addition, it may serve as a basis for the further development of more complex models. For instance, it would be desirable to be able to develop mathematical models to account for the enhanced accumulation of SMP observed during both stressful conditions (nutrient deficiency, toxicity, osmotic shocks), and also in reactors with a high accumulation of biomass, such as membrane bioreactors (MBR s), blanket sludge reactors (UASB) and baffled reactors (ABR), where the SRT is much greater than the HRT.

\section{References}

[1] B.E. Rittmann, W. Bae, E. Namkung, C.-J. Lu, A critical evaluation of microbial product formation in biological processes., Water Sci. Technol. 19 (Rio) (1987) 517-528.

[2] W.C. Kuo, M.A. Sneve, G.P. Parkin, Formation of soluble microbial products during anaerobic treatment, Water Environ. Res. 68 (1996) 279285.

[3] D.R. Noguera, N. Araki, B.E. Rittmann, Soluble microbial products (SMP) in anaerobic chemostats, Biotechnol. Bioeng. 44 (1994) 10401047.

[4] D.J. Barker, D.C. Stuckey, Modelling of soluble microbial products in anaerobic digestion: the effect of feed strength and composition, Water Environ. Res. 73 (2) (2001) 173-184.

[5] C.S. Laspidou, B.E. Rittmann, A unified theory for extracellular polymeric substances, soluble microbial products, and active and inert biomass, Water Res. 36 (2002) 2711-2720.

[6] C.S. Laspidou, B.E. Rittmann, Non-steady state modeling of extracellular polymeric substances, soluble microbial products and active and inert biomass, Water Res. 36 (2002) 1983-1992.

[7] A. Ramesh, L. Duu-Jong, S.G. Hong, Soluble microbial products (SMP) and soluble extracellular polymeric substances (EPS) from wastewater sludge, Environ. Biotechnol. 73 (2006) 219-225.
[8] S.F. Aquino, D.C. Stuckey, Soluble microbial product formation in anaerobic chemostats in the presence of toxic compounds, Water Res. 38 (2) (2004) 255-266.

[9] G.P. Parkin, P.L. McCarty, Production of soluble organic nitrogen during activated sludge treatment, J. WPCF 53 (1) (1981) 99-112.

[10] D.H. Nies, Microbial heavy-metal resistance, Appl. Microbiol. Biotechnol. 51 (1999) 730-750.

[11] N. Mirimanoff, K.J. Wilkinson, Regulation of $\mathrm{Zn}$ accumulation by a freshwater gram-positive bacterium (Rhodococcus opacus), Environ. Sci. Technol. 34 (2000) 616-622.

[12] J.W. Hastings, E.P. Greenberg, Quorum Sensing: the explanation of a curious phenomenon reveals a common characteristic of bacteria, J. Bacteriol. 181 (9) (1999) 2667-2668.

[13] C. Fuqua, E.P. Greenberg, Cell-to-cell communication in Escherichia coli and Salmonella typhimurium: they may be taking, but who's listening? Proc. Natl. Acad. Sci. 95 (1998) 6571-6572.

[14] J.U. Kreft, J.W.T. Wimpenny, Effect of EPS on biofilm structure and function as revealed by an individual-based model of biofilm growth, Water Sci. Technol. 43 (6) (2001) 135-141.

[15] J.A. Robinson, M.G. Trulear, W.G. Characklis, Cellular reproduction and extracellular polymer formation by Pseudomonas aeruginosa in continuous culture, Biotechnol. Bioeng. 26 (1984) 1409-1417.

[16] H. Horn, T.R. Neu, M. Wulkow, Modelling the structure and function of extracellular polymeric substances in biofilms with new numerical techniques, Water Sci. Technol. 43 (6) (2001) 121-127.

[17] R. Kommedal, R. Bakke, J. Dockery, P. Stoodley, Modelling production of extracellular polymeric substances in a Pseudomonas aeruginosa chemostat culture, Water Sci. Technol. 43 (6) (2001) 129-134.

[18] C.S. Laspidou, B.E. Rittmann, Modeling the development of biofilm density includign active bacteria, inert biomass, and extracellular polymeric substances, Water Res. 38 (2004) 3349-3361.

[19] V. de Silva, B.E. Rittmann, Interpreting the response to loading changes in a mixed-culture completely stirred tank reactor, Water Environ. Res. 72 (5) (2000) 566-573.

[20] V. de Silva, B.E. Rittmann, Nonsteady-state modeling of multispecies activated-sludge processes, Water Environ. Res. 72 (5) (2000) 554-565.

[21] S.F. Aquino, D.C. Stuckey, The effect of organic and hydraulic shock loads on the production of soluble microbial products (SMP) in anaerobic digesters, Water Environ. Res. 76 (6) (2004) 2628-2636.

[22] G.-P. Sheng, H.-Q. Yu, X.-Y. Li, Stability of sludge flocs under shear conditions: roles of extracellular polymeric substances (EPS), Biotechnol. Bioeng. 93 (6) (2006) 1095-1102.

[23] Barker, D.J., 1999. Characterisation, production and removal of residual soluble chemical oxygen demand (COD) from anaerobic treatment effluents. Ph.D. Thesis. Department of Chemical Engineering and Chemical Technology, Imperial College, London, pp. 244.

[24] V. Urbain, B. Mobarry, V. de Silva, D.A. Stahl, B.E. Rittmann, J. Manem, Integration of performance, molecular biology and modeling to describe the activated sludge process, Water Sci. Technol. 37 (4/5) (1998) 223-229.

[25] H. Furumai, B.E. Rittmann, Advanced modeling of mixed populations of heterotrophs and nitrifiers considering the formation and exchange of soluble microbial products, Water Sci. Technol. 26 (3/4) (1992) 493-502.

[26] E. Namkung, B.E. Rittmann, Soluble microbial products (SMP) formation kinetics by biofilms, Water Res. 20 (6) (1986) 795-806.

[27] R.E. Speece, Anaerobic Biotechnology for Industrial Wastewaters, Archae Press, Nashville, TN, USA, 1996. 